\title{
CULTURAL AND SOCIO-ECONOMIC DIMENSIONS IN THE CONSERVATION OF BIODIVERSITY
}

\author{
Anoja Wickramasinghe \\ Department of Geography, University of Peradeniya
}

\begin{abstract}
Many countries have ratified the UN Convention on Biological Diversity, and considerable efforts have been made to apply it, at least in the field of policy reforms. Many practical examples drawn from across the world show that conservation has been an integral part of the resource use and survival systems of indigenous communities. In Sri Lanka, patterns of forest resource use have been differentiated not only in relation to the local people's links with the available biological resources; but also as a result of cultural and socioeconomic decisions. The survival strategies of indigenous forest-fringe communities are related to the plant life both of natural forests and of non-forest production systems. Spiritual rituals, food habits and medicinal practices have favoured the conservation of biodiversity. Various aspects of indigenous ethics have also given strong support to conservation. Field studies conducted in Ritigala Strict Natural Reserve suggest that local knowledge of the diversity of the ecosystem is very complex, and that it provides a basis for fuiure conservation strategies. Unless indigenous cultures, knowledge and livelihood systems are respected and recognized, the practical link between survival and conservation will be lost along with a wealth of information.
\end{abstract}

\section{Introduction}

The Convention on Biological Diversity has a number of interrelated dimensions, which challenge the conventional approaches to the conservation of biodiversity by protected area management. It allows individual states to decide how best to conserve biodiversity. By ratifying the Convention, which came into force at the end of 1993, we have expressed our commitment to conserving the biological resources of the country. According to the Convention, the task is so much the broader and more comprehensive in that it is not confined to protected area management. For instance, biodiversity includes "the variability among living organisms from all sources including, inter alia, terrestrial, marine and other aquatic ecosystems and the ecological complexes of which they are part; this includes diversity within species. between species, and of ecosystems" (UNEP, 1992). 
From the point of view of the local people, what is most striking is the variability of the natural world that they know about. They see this variability to be necessary for the wellbeing of both present and future generations.

The provisions of the convention allow each government to take locally appropriate measures in land-use management. Although nothing has yet been done here, either to stimulate practical action or to raise an awareness among those who could contribute most actively to achieving the set goals, the preamble of the convention has drawn attention to the human dimensions of conservation. It recognizes "the close and traditional dependence embodying traditional lifestyles on biological resources and the desirability of sharing equitably benefits arising from the use of traditional knowledge, innovation and practices relevant to the conservation of biological diversity and the sustainable use of its components."

The marriage between conservation and sustainable use has been accepted informally, whether or not the conditions under which it can be put into effect are understood. To achieve a realistic link, the cultural and socio-economic issues related to biodiversity need to be structured into national and local development strategies. New strategies for biodiversity conservation, that incorporate cultural and socio-economic values, are imperative and urgent. This requirement will make for a change in future activities that will be so much the greater because in the past the conservation effort has been concentrated so much on areas with species richness and endemism. According to the Convention the task is more complex, in that it urges respect, preservation and maintenance of the knowledge, innovations and practices of indigenous and local communities that embody traditional lifestyles relevant to the conservation and sustainable use of biodiversity, and also the promotion of the wider application of this knowledge, with the approval and involvement of those who own it at present.

During the Decade for Cultural Development, initiated jointly by the UN Secretary General and the UNESCO Director General in 1988, UNESCO has attempted to persuade those who are involved in development to take up an interest in cultural matters. The World Bank's phrase, "putting people first", the UNDP's notion of "human development", and the academics' maxim, "listen to people first" are evidence of a broad human orientation. In biodiversity conservation, as in forest management, no drastic change towards an ethnocentric approach has yet been promoted in practice. This hesitation may be due to biodiversity conservation having been discussed mainly in the context of forest conservation, or it may be simply due to ignorance of the fact that biodiversity conservation is much broader than nature conservation. The interrelated and complex aspects of cultural diversity and socio-economics are to be found outside the boundaries of protected areas, and so have not attracted the minds of the conservation scientists.

The question unanswered so far is whether any national effort could possibly be made in terms of the well established scientific paradigm, which is autonomous and authoritative, and yet be connected to the human dimension. Many approaches have already been suggested to replace the conventional "top-down" with the "bottom-up" process, and the latter has indeed been connected with people's knowledge and practices. The promotion of biodiversity conservation in a broader context of culture and socio-economics suffers from lack of 2 
knowledge, perpetuated by the absence of research. Since the late 1980s, donor-driven efforts have been made that have paid attention to these aspects, but no systematic approach has yet been made. So far we have no feasible and acceptable framework for action, to build upon the conservation efforts that have been based on the peoples' local initiatives. A great drawback here is our lack of an anthropological sense about "culture" (which in fact is simply a peoples' way of life) in the context of the socio-economic governance that has evolved over generations. Our interest in these lines of thinking is sketchy, and is seen more in relation to forest than to biodiversity conservation. A number of aspects have been taken up to some extent by the interventional agencies. They include indigenous forest management practices, the management of religious forests and "sacred groves", and the strategies of joint forest management. These aspects have been studied with a view to embedding culture and socioeconomics into conservation policies.

This paper attempts to examine how biodiversity conservation can be perceived as an integral part of the lifestyle and the survival strategy, and how the connection between them is structured. Then it goes on to discuss the capacity of cultural and socio-economic ideas to assist in developing acceptable and feasible conservation strategies, aimed at promoting landscape diversity and species variability. It discusses the culturally sensitive features of food and medicinal habits, spiritual rituals, land-husbandry practices and indigenous knowledge of local resources and management. It is shown that culture and socio-economics are parts of the base on which locally sound conservation measures can be developed.

\section{Culture and socio-economics}

One could argue that culture cannot be considered separately, but should be taken into consideration within the framework of socio-economics. In this paper, indeed, cultural matters are discussed more as part of the ecosystem, so as to focus on more specific aspects of them. The livelihood strategies of indigenous communities and their way of life are closely connected with local resources, including the biological ones, and with the diversity of these resources. Rather than focusing merely on the diversity of species, the paper examines the ecosystem diversity to which local communities contribute as stewards. No sharp division can be made between culture and socio-economics; most of the community features in question pertain to both. This is particularly true of those communities that have a long history of forest-related survival, as is the case of the indigenous communities of Ritigala and of the southern fringe of the Adan's Peak Wilderness. The differences in their way of life reflect spatial variations in the biological resources among the country's ecosystems. Cultural and socio-economic features are connected with the evolutional history of the area and the communities. The length of the period for which they have occupied the terrain has enabled them to accumulate a wealth of knowledge. For instance, there is a clear difference in the human/forest interface as between the fringe dwellers who live adjacent to and below the northern boundary of the Adam's Peak Wilderness, who are relatively recent arrivals, and that of the traditional communities in the south, whose history of occupation goes back to time immemorial. In Ritigala, socio-economically, from the point of view of benefits and their geographical locations, the forest resources are of some importance to all fringe dwellers. Culturally, forest resources are closer to the way of life of the traditional people, as part of the holism of their culture, and in connection with spiritual rituals and with the 
livelihood strategies that are related to the forest resources. This complex relationship implics that it is not only the socio-economics of the forest resources that have an impact upon the conservation of biodiversity, but also the belief systems, ethics, and behavioural patterns of non-forest dwellers.

In Ritigala. for example the way of life of those who claim to be descendants of the communities that lived on hunting and gathering has a stronger connection with the local resources than does that of the others who have only been in the area for a few generations. The management systems of the traditional communities are strongly ethnocentric, and conservational strategies are an integral part of community life. Culture is part of the conservation and survival systems of the people.

Three topics related to culture and socio-economics are discussed here:

- how the diversity of the ecosystems which local people depend upon for survival has an impact on conservation:

- the strong socio-economic features which reflect the nature of the relationship between survival strategies and local biological resources;

- whether conservation could make a contribution to uplifting the living standards of local communities, and thereby strengthen their partnership in the general conservation effort, if impediments to community control over local resources were to be removed.

\section{Ecosystem diversity for sustainable survival}

The maintenance of ecosystem diversity and variation, both inside and outside the forests, has been a major concern of traditional people. Many communities in Sri Lanka have long practised principles of stewardship in their management of landscape variability. in the forests and farmlands. For survival, both natural resource sustainability and socio-economic sustainability are important. The latter is connected with the linkages between people and biodiversity. According to the Panos Media Briefing (1995): "Biodiversity is essential to the world's ability to maintain its current level of food supplies; ... according to the FAO, a $60 \%$ increase in food output is necessary in the next 25 years ... Biodiversity also provides the key ingredients for medicines. Around $80 \%$ of the world's population is at least parly dependent upon traditional medicine and medicinal plants ... ".

The responsibility of individual countries and their communities in this effort is very great, because ecosystem and species diversity can only be assured by local action. The communitics have both direct and indirect experience of the need for landscape variability to meet their survival needs. It is not only the material output that they require, but also the non-material functions of biodiversity. A study conducted in the dry zone in Labunonuwa in 1995 revealed that village ecosystems would not support the livelihood of the people if their interrelated and interdependent parts were not managed integrally. All the land-use elements are located in a specific pattern. so as to ensure a balance in their functions: natural forests; riverine ecosystems; shrubs; woodlands known as hinna; the village forests known as gankele; the reservations around the village tanks, wewpitiva; and around the irrigation lanks. kattakadiwa: paddyfields; chena (slash and burn) land; and gammedela, the central area of 
the village, comprising both dwellings and the centres of service and community work. These elements of the village ecosystems have not been manipulated arbitrarily. The resourcereceiving segments and those that depend on other segments are placed in a hierarchical order, taking morphological variations into account. Segments such as forests and wewpiti are maintained so that they feed other segments lower down the land-use gradient. The relations and interactions between segments are of primary concern. Forest and large trees are respected as the places where spiritual rituals take place. The guiding principle behind the maintenance of variability in land use or in village ecosystems has been the interest of traditional people in maintaining the sources of their survival as an integral whole.

For obvious reasons, forests in such systems occupy the higher areas. The functions of the forest in maintaining village supplies, for irrigation and other uses, while providing a multitude of products are well recognized. If the interest of the traditional people in land was only in its agricultural potential, there would be no ecosystcm variations. The hundreds of acres that are under wewpitiva, gankele, and kattakaduwa reflect the people's intcrest in variability. Resources possess more for them than the utilitarian values that directly satisfy their need for food. In addition, the resources are maintained to satisfy the environmental requirements, to filter water, trap sediment, stabilize the land that is susceptible to erosion, ctc. In practice, no individual rights are maintained over the areas whose functional benefits are for the sustention of community survival. It is considered that everybody is responsible for maintaining these common lands. The equal rights of the community members are respected and mutually recognized.

Even in areas with a long history of external interventions, and experience of a considerable conversion of land to commercial agriculture, concern for ecosystem variability, diversity, and integrity is much greater than one might expect. The local people themselves maintain thousands of miles of riverine vegetation strips, primarily for service functions, and secondarily for production. In the wet zone, the management of wanatha land between the paddy fields and the plantations above, shows that the concept of biodiversity conservation is cmbedded in local resource management systems.

\section{Biodiversity and survival needs}

The traditional people have multiple survival sources. Their contacts are not determined by the legal ownership of the resources, but by how thcy must be maintained to support day-today living. This requirement results in the local community being involved in the management of local resources and in the establishment of special patterns in the lifestyles of people and in the utilization of the local flora. For a variety of non-farm food and medicinal products, people have the habit of going back to the common land, including the forests. Very large quantities of products that are not often found in other areas are supplied by the forests. other common land. and micro-habitats in the farms. fences, hedges. drainage and river banks. They include major carbohydrate sources and other food ingredients, flavourings, herbs, leaves, roots, and fruits. Farm food production has undergone a transition, from greater diversity to a narrow range of crops, or even monoculture. For this reason there has been a great increase in the importance of the contribution of natural forests and common land. The diversity of the resources to which people have access enables them to maintain a greater variey in their eating habits. 
Table 1 - Ranking of the uses of forest products in eleven communities (number in brackets is the percentage)

\begin{tabular}{|c|c|c|c|c|c|c|c|c|}
\hline \multirow[t]{2}{*}{ Community } & \multicolumn{8}{|c|}{ Priority order of the uses in terms of percentage } \\
\hline & 1 & 2 & 3 & 4 & 5 & 6 & 7 & 8 \\
\hline Hangarapitiya & fuelwood & $\begin{array}{l}\text { vegetable } \\
\text { (83) }\end{array}$ & $\begin{array}{l}\text { medecine } \\
(79)\end{array}$ & $\begin{array}{l}\text { binding } \\
(68)\end{array}$ & $\begin{array}{c}\text { porridge } \\
(60)\end{array}$ & $\begin{array}{c}\text { timber } \\
(53)\end{array}$ & $\begin{array}{l}\text { food } \\
(51)\end{array}$ & $\begin{array}{c}\text { fruits } \\
\text { (13) }\end{array}$ \\
\hline Maliboda & fuelwood & $\begin{array}{c}\text { bindig } \\
(87)\end{array}$ & $\begin{array}{c}\text { vegetable } \\
(81)\end{array}$ & $\begin{array}{c}\text { medecine } \\
(75)\end{array}$ & $\begin{array}{l}\text { timber } \\
(73)\end{array}$ & $\begin{array}{l}\text { food } \\
(68)\end{array}$ & $\begin{array}{c}\text { porridge } \\
(48)\end{array}$ & $\begin{array}{c}\text { fruits } \\
\text { (33) }\end{array}$ \\
\hline Erathna & fuelwood & $\begin{array}{c}\text { vegetable } \\
(83)\end{array}$ & $\begin{array}{l}\text { binding } \\
(74)\end{array}$ & $\begin{array}{l}\text { medecine } \\
(71)\end{array}$ & $\begin{array}{l}\text { food } \\
(68)\end{array}$ & $\begin{array}{l}\text { porridge } \\
(61)\end{array}$ & $\begin{array}{l}\text { timber } \\
(57)\end{array}$ & $\begin{array}{c}\text { fruits } \\
(24)\end{array}$ \\
\hline Palabaddala & fuelwood & $\begin{array}{l}\text { Food } \\
(92)\end{array}$ & $\begin{array}{l}\text { vegetable } \\
\text { (88) }\end{array}$ & $\begin{array}{l}\text { binding } \\
(85)\end{array}$ & $\begin{array}{l}\text { medecine } \\
(82)\end{array}$ & $\begin{array}{l}\text { porridge } \\
(72)\end{array}$ & $\begin{array}{c}\text { fruits } \\
(65)\end{array}$ & $\begin{array}{c}\text { timber } \\
(51)\end{array}$ \\
\hline Kudawa & fuelwood & $\begin{array}{l}\text { timber } \\
(97)\end{array}$ & $\begin{array}{l}\text { binding } \\
(84)\end{array}$ & $\begin{array}{l}\text { medecine } \\
(80)\end{array}$ & $\begin{array}{c}\text { vegetable } \\
(77)\end{array}$ & $\begin{array}{c}\text { porridge } \\
\text { (71) }\end{array}$ & $\begin{array}{l}\text { food } \\
(58)\end{array}$ & $\begin{array}{c}\text { fruits } \\
(41)\end{array}$ \\
\hline Dehenakanda & fuelwood & $\begin{array}{c}\text { vegetable } \\
(96)\end{array}$ & $\begin{array}{c}\text { timber } \\
(92)\end{array}$ & $\begin{array}{c}\text { binding } \\
(83)\end{array}$ & $\begin{array}{l}\text { porridge } \\
(82)\end{array}$ & $\begin{array}{l}\text { medecine } \\
(81)\end{array}$ & $\begin{array}{l}\text { food } \\
(76)\end{array}$ & $\begin{array}{c}\text { fruits } \\
(28)\end{array}$ \\
\hline Waleboda & fuelwood & $\begin{array}{c}\text { vegetable } \\
(90)\end{array}$ & $\begin{array}{l}\text { binding } \\
(87)\end{array}$ & $\begin{array}{c}\text { porridge } \\
(76)\end{array}$ & $\begin{array}{l}\text { timber } \\
(70)\end{array}$ & $\begin{array}{l}\text { medecine } \\
(63)\end{array}$ & $\begin{array}{l}\text { food } \\
\text { (61) }\end{array}$ & $\begin{array}{c}\text { fruits } \\
(24)\end{array}$ \\
\hline Landuyaya & fuelwood & $\begin{array}{c}\text { vegetable } \\
(82)\end{array}$ & $\begin{array}{l}\text { binding } \\
(77)\end{array}$ & $\begin{array}{c}\text { medecine } \\
\text { (73) }\end{array}$ & $\begin{array}{l}\text { timber(52) } \\
\text { fruits(52) }\end{array}$ & $\begin{array}{c}\text { porridge } \\
(50)\end{array}$ & $\begin{array}{l}\text { food } \\
(5)\end{array}$ & - \\
\hline Friedland & fuelwood & $\begin{array}{c}\text { timber } \\
(73)\end{array}$ & $\begin{array}{l}\text { porridge } \\
\text { (33) }\end{array}$ & - & - & - & - & - \\
\hline Meeriyacotte & fuelwood & $\begin{array}{c}\text { timber } \\
(88)\end{array}$ & $\begin{array}{l}\text { other } \\
(85)\end{array}$ & $\begin{array}{l}\text { binding } \\
(81)\end{array}$ & $\begin{array}{c}\text { vegetable } \\
(56)\end{array}$ & $\begin{array}{l}\text { porridge } \\
(44)\end{array}$ & $\begin{array}{l}\text { medecine } \\
(41)\end{array}$ & $\begin{array}{c}\text { fruits } \\
(15)\end{array}$ \\
\hline Rajamale & fuelwood & $\begin{array}{l}\text { Other } \\
(30)\end{array}$ & $\begin{array}{c}\text { porridge } \\
(17)\end{array}$ & - & - & - & - & - \\
\hline Overall & fuelwood & $\begin{array}{c}\text { vegetable } \\
(83)\end{array}$ & $\begin{array}{c}\text { bindig } \\
(79)\end{array}$ & $\begin{array}{c}\text { medecine } \\
(74)\end{array}$ & $\begin{array}{c}\text { timber } \\
(65)\end{array}$ & $\begin{array}{c}\text { porridge } \\
(60)\end{array}$ & $\begin{array}{l}\text { food } \\
(59)\end{array}$ & $\begin{array}{c}\text { fruits } \\
(34)\end{array}$ \\
\hline
\end{tabular}


The use of forest resources depends on needs, food habits, indigenous knowledge, processing technology and skills. On the fringe of the Adam's Peak Wilderness, 59\% of houseliolds use various roots, fruits, nuts, and seeds to augment their staple diets, $83 \%$ use leafy vegetables from the forest in curries, $60 \%$ use forest products for making porridge, $43 \%$ gather fruit, and for $74 \%$ the forest is a primary source of medicinal products. Table 1 shows that the survival of these fringe communities is strongly dependent on the forest, which is why they want to take the responsibility for protecting it against destruction. The total number of uses recorded in a sample study was 638 in Dehejakanda, 635 in Palabaddala, 608 in Kudawa, 585 in Maliboda, 571 in Waleboda, 538 in Erathna, 520 in Meeriyacotte, 507 in Hangarapitiya, 206 in Friedland, and 147 in Rajamale. Although similar patterns have been observed in the dryzone study in Ritigala, the difference there is that forest products make a greater contribution to cash income, so that subsistence products are given a lower priority.

The forest products include major food items, vegetables, beverages, porridge, fnuits, medicinal products, materials for making utensils, binding materials, and materials for home-based industries. It is reported that timber is collected only occasionally, whereas firewood is an essential everyday product. Some 21 species are used as staple dietary constituents - mainly three kinds of tubers, one climber and two trees. Raw vegetable products are obtained from about 34 species. About 15 species provide products to make porridge. Fruit is obtained from 24 forest species. About eight forest species are used in preparing beverages. The relation between the local flora and indigenous medicinal practices presents the most complex picture. This includes not only healing, but also day-to-day food habits. The food and medicinal values are not separated, but rather, in the local people's experience, the forest resources provide "health foods" (Wickramasinghe, 1995). Some 214 species have been recorded as having medicinally important ingredients in this sense.

What is really important is not a simple inventory of what species or parts of the plant the people use, but how their day-to-day life and habits are related to the diversity of the flora, which is what has motivated them to manage the resources.

\section{Culture and biodiversity conservation}

Our formal interest in the cultural dimensions of conservation is rather new, although there has been an interest at the practical level for a long time. Attempts to understand the linkages have been made during the last decade or so. No ways are known as yet for incorporating them into action, particularly in development programmes. This is simply because cultural aspects have evolved as part of the integral whole, and as such can only be taken into account by social processes. The cultural aspects of biodiversity conservation are subject to the rule that the human/resource interface is heterogeneous and changes spatially over time. For the purposes of maintaining the country's biogeographical variations, many lessons can be learned from the traditional way of life of the people. What is needed is to find ways and means of conserving the natural ecosystems, the habitats, and the indigenous flora without further extinctions taking place. For instance, in Ritigala, mora (Dimocarpus longana) is the "gold of the forest", and gal-siyambala (Dialium ovoideum) is the "source of cash". On the southern fringe of the Adam's Peak Wilderness, the important source of cash is kitul (Caryota urens). The pattern also varies along the forest periphery, between communities, 
and according to resource availability. While well marked spatial variations are associated with the locally available flora, there are also variations between communities as to the importance placed on locally available biological resources. For instance, the plantation communities on the northern fringe of the Adam's Peak Wilderness are less concerned about the resource diversity of the forest than the communities in the south. Not only is their way of life different, being based on plantation work to produce market commodities, but also they are less knowledgeable about the uses of resources, their diversity both in composition and space, ways of processing them. etc. There is a similar, but not identical situation in Ritigala. between the descendants of the Veddhas (the communities that lived on hunting and gathering) and the people who can claim only a short history in the area.

Local initiatives in conserving the multiple-value biological resources of non-forest land are also noteworthy. They include an interest in individual trees, as well as in the management of the common land and the sacred groves. The reasons for managing trees in isolation and in various habitats are related to thcir utilitarian value, economic and production benefits. aesthetic value, and religious and spiritual rituals. Natural habitats and forest trees often have special significance as symbols of spirits. The conservation practices of traditional communities are part of their belief system. According to Buddhist belief the forest trees are "lords of the forests" (vanasapti in Pali). Trees and forests are revered by the traditional people, who believe that they are the resting places of spirits and gods. Some species are cven more especially revered, eg bo (Ficus religiosa). In Ritigala, spiritual rituals are performed under huge trees on non-forest land. Nuga (Ficus altissima), mee (Madthuca longifolia). tamarind (Tamarindus indica). and neem (Azadirachta indica) have specific supcrnatural powers comnected with them. Neem is maintained widely for its ability to cure and prevent the spread of discases. It is known as a symbol of the goddess Paththini, who is believed to be able to help cure disease and relieve pain.

Elderly people in Galapitagala, Kaluebe and Muriyakadawala do not like to hear that outsiders consider Ritigala as a biophysical object, while they themselves see it as the "excellency" of the district. The same view has been noted in Walcboda and Erathna. in relation to the Adam's Peak Wilderness, because of its importance for religion, forest gods, and spiritual rituals. The people start each day by paying reverence to the forest. Abusive exploitation of forest resources will be punished by the god Ayyanayake. the god of the Ritigala forests. The god of the land. Mahasen, is the superpower whose blessing is essential if one is to live safely and to obtain a harvest from the forests. Before they enter the forest people hang twigs on the branches of huge trees that are known to be the resting places of the local gods and spirits. The superpowers are expected to put limits on the harvest of nature's products, and to impose sanctions on over-exploitation and harmful behaviour. Even the pilgrims who climb Adam's Peak to revere the foot print of Lord Buddha make vows to the god Sumana Saman. the god of the wilderness area. They also hang twigs on branches of huge trees near their entry points to the forest, and plead for their safety in the wilderness. The reasons for having places for meditation in the forests, and for managing the sacred groves. particularly around monasteries, are to be found in Buddhist philosophy, which enjoins a resort to natural habitats. Ecological knowledge of biodiversity has given rise to social regulations. under which power to impose sanctions on harmful behaviour is allocated 
to local gods and spirits. The notions of sacredness and taboo are complex; participatory research over a long period is needed to understand them.

Ecological knowledge has been utilized to promote diversity on non-forest lands. The historical evolution of the mosaic of home gardens, trees on farmlands, live fences, etc, reflects the way in which local communities have cultivated diversity with no external guidance or incentives. The evolution of traditional cultures has arisen from local resources. In similar situations the Navdaya Team (1993) has expressed the view that cultural diversity and biological diversity go hand in hand.

Indigenous forest management systems like those in Ritigala, in which a high value is placed on group solidarity and reciprocity, cannot be found on most other forest fringes. The cultural values and religious practices on which these systems are based have strengthened the feeling of inheritance. The forest is considered as the people's own property, despite the fact they have no ownership rights and have been excluded from the role of forest protectors. When compared with the situation in other areas, and with the communities that do not have a long history in Ritigala, the descendants of the Veddhas have substantially retained their cultural systems, their practice of group sharing, and their holistic view of the forests. Most other communities have succumbed to outside values introduced by economic "progress" and the increase in external communication.

This paper does not say that the way of life of people all across the country is closely dependent on natural habitats, but only that where such dependency exists it must be respected and recognized as a local motive for conservation. This is simply because, if it were not for the traditional food, medicinal and survival strategies, as well as for the belief systems, biodiversity would have been destroyed much faster than has actually been the case. People's motives for saving the land-use and ecosystem diversity, and maintaining local flora, are related to well established survival strategies, in their cultural contexts.

\section{Economic motives}

There are many economic motives for the people to maintain diverse production systems, or diverse ecosystems, both inside and outside the natural forests. Shiva (1996) has proposed a biodiversity-based productivity framework, which allows farmers to evaluate agricultural changes on the basis of the needs of the land and the needs of farming communities, and which also allows comparisons to be made across systems. Her preliminary analysis of results has revealed that when diversity is taken into account, the return to farmers is greater from mixed systems than from monocultures. "On the one hand, diverse systems produce more nutrition per acre when all crops and all crop parts are included. On the other hand farmers save money by substituting purchased inputs such as chemicals and fertilizers with internal inputs provided by biodiversity" (Shiva, 1996). In fact the contributions of home gardens to farm households and to environmental sustainability can be given as examples of indigenous strategies for sustainable survival.

Areas or ecosystems rich in diversity have been proclaimed as protected or conservation areas. For the people, however, because of their economic, cultural and environmental 
relationships with the forest, there has been no frontier between forest resources and their own livelihoods. The history of forest-fringe communities shows that forest resources have either directly supplemented the income derived by the households and the communities from non-forest activities, or provided free commodities which would otherwise have been bought from the outside. The part played by forest products in the economies of eleven community clusters (Table 2) shows the importance of forest-resource based income for traditional communities, and also a great spatial variation in this aspect.

Table 2: The share of forest products in the economies of local communities

\begin{tabular}{ll}
\hline Community & Percentage \\
\hline Hangarapitiya & 27 \\
Maliboda & 58 \\
Erathna & 33 \\
Palabaddala & 44 \\
Kudawa & 58 \\
Dehenakanda & 18 \\
Waleboda & 56 \\
Landuyaya & 05 \\
Friedland & 01 \\
Meeriyacote & 01 \\
Rajamale & 01 \\
\hline
\end{tabular}

Source: Wickramasinhe (1995)

The location-specific nature of resource-use patterns supports the view that the picture cannot be generalized. For instance, for all the 11 communities covered by the Adam's Peak Wilderness study, no uniformity can be detected in regard to the priority species for income opportunities. The outstanding feature emerging from the information summarized in Table 3 is that the non-indigenous communities (Friedland, Meeriyacotte, and Rajamale) have very little concern for the biological resources of the forest. Except in Kudawa and Waleboda, the first priority for income generation is placed on one single species, kitul (Caryota urens). In fact kitul tapping has sometimes been reported as the major source of employment, and it is widely considered as being a primary source of household income. Because of the annual and inter-seasonal variations, no accurate information on income was collected, but the average was in the range of Rs 1500 to 6000 per month. To meet the increasing market demand for kitul products, it has been planted on household land, in home gardens, and on cropland. This sort of activity is exactly what is needed in the future for the better management of forest biodiversity, and also to promote biodiversity on non-forest land. Such local initiatives cannot be spread more widely by interventions, unless the necessary traditional skills, technology and knowledge are extended by social processes.

In the dry zone, a wide range of forest products is used for day-to-day survival, but with the increasing market demand the income derived from selling forest products has also greatly increased. The herbs, gal-siyambala (Dialium ovoideum), bin-kohomba (Munronia pumila), honey, and other medicinal products are the primary sources of cash income. A detailed investigation in four communities has revealed that the greatest share of their income comes 
Table 3 - Use of forest resources by eleven communities primarily for income (number in brackets is the percentage)

\begin{tabular}{|c|c|c|c|c|c|c|c|c|c|c|c|}
\hline & \multicolumn{11}{|c|}{ Site } \\
\hline & 1 & 2 & 3 & 4 & 5 & 6 & 7 & 8 & 9 & 10 & 11 \\
\hline Canota urens & $17(100)$ & $29(38)$ & $22(31)$ & $27(38)$ & $31(48)$ & $5(9)$ & $17(24)$ & $3(6)$ & 0 & 0 & 0 \\
\hline Resins & $3(4)$ & $3(5)$ & $4(6)$ & $10(14)$ & $5(8)$ & $4(7)$ & $19(27)$ & $4(7)$ & 0 & $2(7)$ & 0 \\
\hline Elettaria ensal & $5(6)$ & $6(10)$ & $2(3)$ & $11(15)$ & $10(16)$ & $7(13)$ & $12(17)$ & $2(4)$ & 0 & 0 & 0 \\
\hline Coscinium fenestratum & $6(8)$ & $8(12)$ & $12(18)$ & $22(30)$ & $32(49)$ & $8(14)$ & $26(36)$ & $2(4)$ & 0 & $1(3)$ & 0 \\
\hline Calamus rotang & $8(11)$ & $1(2)$ & $4(6)$ & $2(3)$ & $5(8)$ & $5(9)$ & $13(18)$ & 0 & 0 & 0 & 0 \\
\hline Ochlandra stridula & $3(t)$ & $4(6)$ & $1(2)$ & $4(6)$ & $5(8)$ & $+(7)$ & $16(23)$ & 0 & 0 & $5(18)$ & 0 \\
\hline Garcinia cambogia & $2(3)$ & $9(14)$ & $3(4)$ & $13(18)$ & $5(8)$ & $7(13)$ & $2(3)$ & $1(2)$ & 0 & $5(18)$ & 0 \\
\hline Honey & $2(3)$ & 0 & $1(2)$ & $1(1)$ & $5(8)$ & $3(6)$ & $4(6)$ & $1(2)$ & 0 & 0 & 0 \\
\hline Pandanus sp. & $2(3)$ & $2(3)$ & $4(6)$ & $4(6)$ & $10(16)$ & $5(9)$ & $10(14)$ & $2(4)$ & 0 & 0 & 0 \\
\hline Fodder & $5(6)$ & $2(3)$ & $8(12)$ & $2(3)$ & $5(8)$ & $t(7)$ & $4(6)$ & 0 & 0 & 0 & 0 \\
\hline Cinnamomum multiflorum & 2(3) & $2(3)$ & $1(2)$ & $5(7)$ & $5(8)$ & $+(7)$ & $2(3)$ & 0 & 0 & 0 & 0 \\
\hline Shoreasp. & 0 & 0 & 0 & 0 & $6(9)$ & 0 & $4(6)$ & 0 & 0 & 0 & 0 \\
\hline Namal renu & 0 & 0 & 0 & 0 & 0 & 0 & 0 & 0 & 0 & 0 & 0 \\
\hline Kollankiala & 0 & 0 & 0 & 0 & 0 & 0 & 0 & $2(3)$ & 0 & 0 & 0 \\
\hline Pancratium zeylanicum & 0 & 0 & 0 & 0 & 0 & 0 & 0 & $1(2)$ & 0 & 0 & 0 \\
\hline Jatamansa & 0 & 0 & 0 & 0 & 0 & 0 & 0 & $1(2)$ & 0 & 0 & 0 \\
\hline Scyphostachys coffaeoides & 0 & 0 & 0 & 0 & 0 & 0 & 0 & $1(2)$ & 0 & 0 & 0 \\
\hline Total & 55 & 66 & 62 & 101 & 124 & 56 & 129 & 20 & 0 & 13 & 0 \\
\hline $\begin{array}{l}\text { te 1-Hangarapitiya } \\
\text { 6-Dehenakanda } \\
\text { 11-Rajamale }\end{array}$ & $\begin{array}{l}\text { aliboda } \\
\text { aleboda }\end{array}$ & & $\begin{array}{l}\text { athna } \\
\text { induyaya }\end{array}$ & $\begin{array}{l}4-\mathrm{P} \\
9-\mathrm{Fr}\end{array}$ & $\begin{array}{l}\text { addala } \\
\text { lland }\end{array}$ & $\begin{array}{r}5-1 \\
10-1\end{array}$ & $\begin{array}{l}\text { dawa } \\
\text { eriyaco }\end{array}$ & & & & \\
\hline
\end{tabular}


Interest in potential sources of income is the result of a number of considerations. The first is the irregularity and unreliability of income derived from farming and other activities. Agriculture, the major source of employment, is prone to downturns due to fluctuations in rainfall and damage by wildlife. The second is the higher income from forest gatherings. For instance, the net income per day is in the range of Rs 300-400 for both gal-siyambala and bin-kohomba, while for honey collecting it is Rs. 430-600. Although these are seasonal activities, the income from them compares well with a daily wage of Rs 80-120. The third is that people want to continue to be in contact with their inherited forest resources. The indigenous people believe that it is their responsibility to follow the rules of their ancestors on forest utilization, although the motive for gathering has changed from subsistence to cash. Their socially driven activities are connected with the traditions of group gathering, equal sharing, and mutual respect for the rights of the communities who inherit the history of the territory. For sustainable biodiversity conservation one cannot overlook such motives - they make the desirable strategies acceptable.

\section{Indigenous knowledge in local initiatives}

The cultural heritage of a local community includes its knowledge system. Over the generations the system has become an integral part of the conmunity. It tends to reflect how people perceive biodiversity and how they have internalized its management. The US National Council (1992), in its discussion of a "Research Agenda for Development Agencies", stressed the view that research should promote the application of local knowledge to modern management. The studies conducted in Sri Lanka reveal that the conservation practices that have evolved around people's distinctive knowledge are complex and difficult to elicit. Knowledge is the property of the community; it covers ecosystems, composition, spatial relationships, distribution, seasonalities, uses, the phenological cycles of species, harvesting methods, processing, and also the social regulations under which rights of the communities and the limits to resource utilization are determined. These aspects are important, not only for local community involvement in biodiversity conservation, but also in appraising the resources. Our information about the local uses of biological diversity and about traditional knowledge systems in general is sketchy. The people have developed special skills, techniques and knowledge in using the biological resources. In Bangalore in India, a system of "community registers" has been started to document local uses of biodiversity and the related knowledge, skills, and technology (Bhatia et al., 1966). According to local people, lessons learned in Ritigala show that the continuity of local knowledge of biological resources is an indicator of sustainable utilization. With regard to certain aspects, particularly with regard to the location of scarce resources, those who have the knowledge are reluctant to discuss the details with outsiders. One reason is that it is against traditional rules. Another is that they believe that the exposure of scarce resources to outsiders, who have no knowledge of the importance of the species, or of the appropriate harvesting and utilization technology, will lead to the destruction of the resource base on which the people depend.

Research in Ritigala on the indigenous knowledge of biodiversity reveals that knowledge of ecosystem diversity and spatial distribution are equivalent to rapid appraisals of the situation. For instance, the forest/ non-forest boundary has been recognized on the basis of internal characteristics, and the differences are related to both natural and human manipulations. 


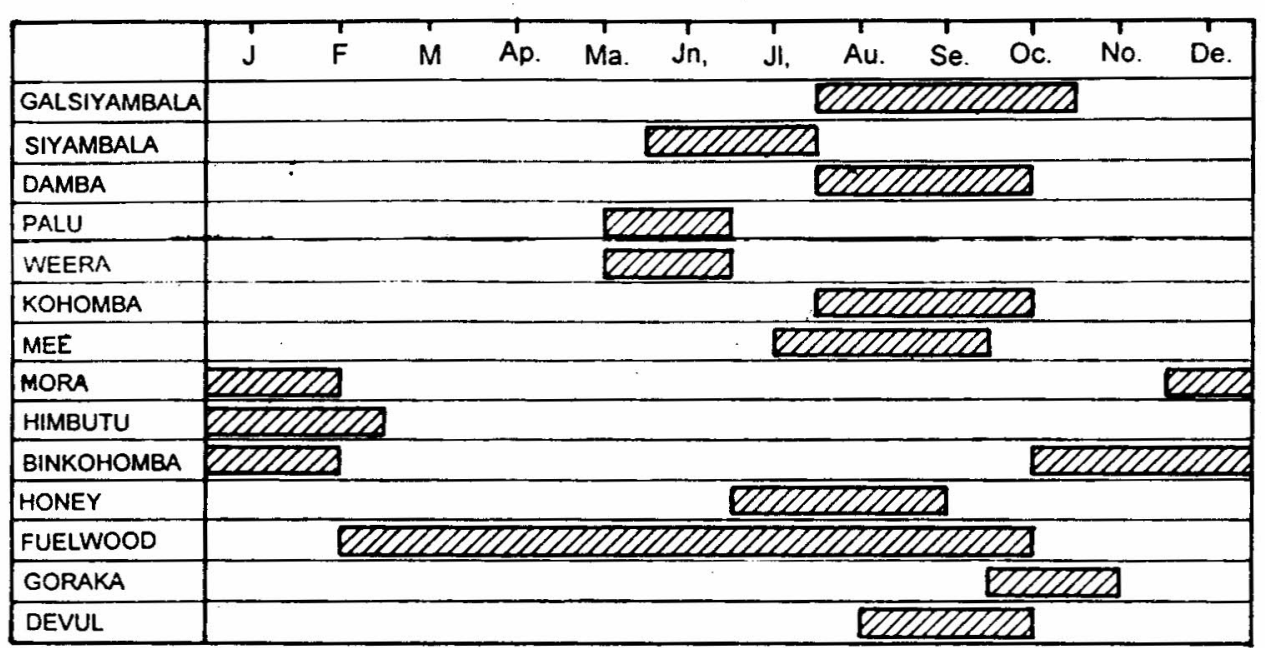

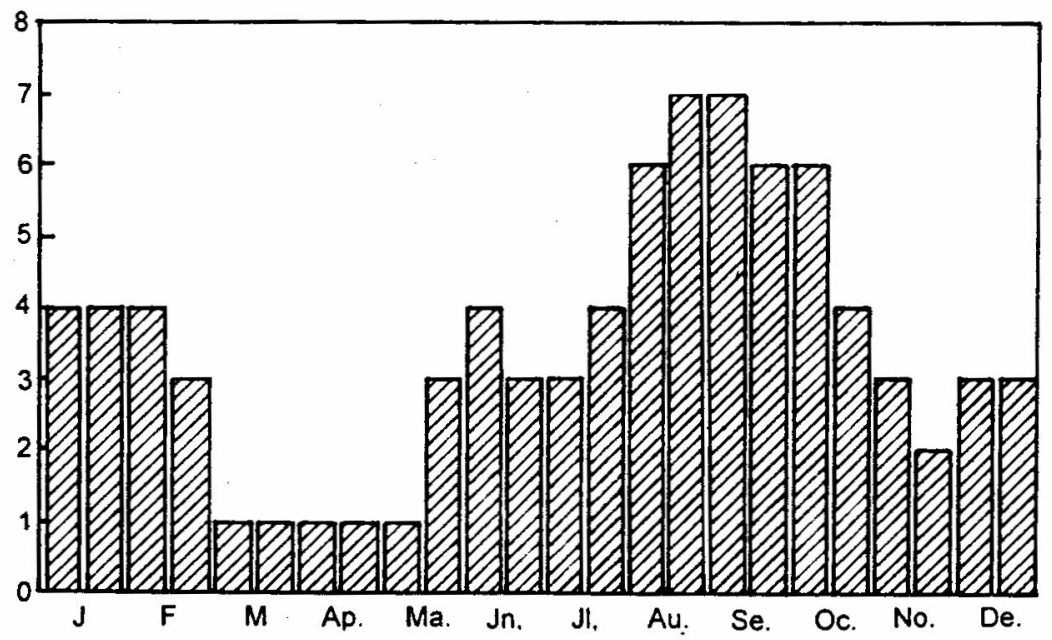

Figure 1: Seasonalities in the availability of forest products 
The forest is perceived as a heterogeneous entity, composed of about 22 micro-ecosystems (Wickramasinghe, 1996). These systems have been named for their predominant species or products, or well marked features such as cliffs, plateaux or drainage. Their names became familiar to the people involved in ecosystem mapping in 1995. Those that are based on species names such as goraka (Garcinia cambogia), kaluwara (Diospyros ebenum), una (Bambusa vulgaris), etamba (Mangifera zeylanica), halmilla (Berrya cordifolia), na (Mesua ferrea), etc, point to the prevalence of these species. The areas described as palaturukanda (meaning a hill carrying fruit producing species) and ausadakanda (meaning a hill with medicinal species) point to the fact that knowledge of resource distribution has a long history. The recurrence of particular species in the names is taken as an indication of similarities in habitats.

From the point of view of research and planning, local knowledge on the seasonalities of forest products is very useful. It provides information on the annual cycle of lorest product availability, which in turn demonstrates the nature of people's contacts and involvement. The annual cycle covers 14 items, some of which are found only in the forest interior, while others are also found on non-forest peripheral land (see Fig. 1). These seasonal patterns help to construct an overview of the resource contacts of different user groups and also of ways and seasons to study the human/forest links. The transmission of local knowledge of the ecosystem from ancestors to later generations, the social contacts through which it is transmitted, and the first hand local experience from which it has been evolved all have a direct connection with the integrity of the community.

Coupled with this internalized system of indigenous knowledge on biological resources, there is respect for the social regulation that is to be followed by members of the community who have internalized the strategies of biodiversity conservation. Respect for the knowledgeable and experienced senior members of the communily, for the rights of the others, for group engagement in procuring resources, and for equal sharing, reflects community-centred resource management. These regulations are, of course, related to lifestyles in which reciprocity and collectivity are valued in day-to-day living. The perception of inheritance of the local resources, which have been managed as the people's own property, raises a number of questions relating to rights to the local biological resources and to the people's potential contribution to protection and management, as against the oflicial responsibility of the state. What is needed to fulfill the requirements of the UN Convention on Biological Diversity at the local level is a form of social or community control, such in fact as has been in operation since before the local resources were declared to be the property of the state. Communitybased conservation is an internalized process in which biological resources and cultural aspects are interrelated. How these interrelations can be maintained without depleting the resources can be understood only by a process of communication. There is no doubt that indigenous knowledge has been the factor that has influenced the process of promoting biodiversity outside natural ecosystems. The home-garden agroforestry systems, the management of the vegetation remaining on cultivated land, and of the new species introduced into the rural landscape are all symbols of local initiatives. The most crucial issues are:

- how to combine indigenous with scientific knowledge,

- how to combine traditional methods with modern technology,

- how to extend and promote conservation outside protected and conservation areas, 
- how to motivate local communities and external agencies to collaborate.

Answers to local problems are still being sought, and in the meantime no local action is yet being promoted on the lines of the Convention.

\section{Discussion and conclusion}

The government has ratifiied the UN Convention on Biological Diversity to show its willingness to collaborate in global concerns. Neither the principles nor the concerns in question have been drawn from the (spatially diverse) local context, and so the commitment has not been internalized. To put the Convention into operation and to regain contact with reality, Sri Lanka has to turn back to community initiatives. What is needed is biodiversitybased development. It requires policy clanges as well as changes in national priorities. For instance, the country has to turn away from conventional forestry development and conservation programmes aimed at specific targets, such as industrial plantations of fastgrowing exotics, and protected areas, and also from all the present kind of developments that deal with land husbandry.

The agriculture and forestry sectors have already damaged local biodiversity, and have facilitated a process of externalizing the interventions. There is enough scattered evidence of other concepts to which the country could turn back. The innovations of indigenous communities are diverse, and are based on local resources. The fragmentation of such innovation and of local motivation, that has been caused by intervention and modernization, has now been recognized. It has happened because these interventions have neither been internalized nor understood, and because local participation has not been secured. The interventions have compartmentalized systems rich in biological resources. The time has come to abandon a number of the faulty assumptions on which such interventions have been based.

Self-evident examples point to the fact that local people know the importance of biodiversity and have well grounded prospects of restoring biodiversity-based survival systems. The traditional social systems need to be reactivated wherever possible, and people must be empowered to organize themselves for collective decision making and local action. The limitations of scientific or technological approaches must be accepted, and future action must build upon the traditional and integrated approaches of the local people. Legislation has limitations and advantages. The limitations can be disastrous when local initiatives are excluded. Rights to conservation and the strength of a dominant cultural context have also bcen excluded. The few advantages of legislation, relating to the sanctions against abusive exploitation, have not been enforced to the degree that might have been expected.

The effort of biodiversity conservation must be extended beyond the houndaries of protected areas. and to this end the participation of all sectors of society is essential. In the past, the state has attempted to proclaim its rights to the forests, commons and reservations, ie to all the systems that harbour a greater diversity, and it has also promoted the modernization of production methods. Litle recognition has been given to the rights of the people who are dependent upon local resources. Their knowledge, and the social context of their lives, must be built into conservation strategies to connect these strategies with day-lo-day survival. State policies have led to interventions that have unintentionally reduced the diversity of husbandry systems on non-forest land. Further intervention on state owned land has worsened the 
situation. These consequences of present policies imply that a great change is needed, to begin a new development and conservation process with local initiatives, from which the socio-economic and cultural context must not be excluded. Over the years, approaches to biodiversity conservation have been paternalized. The socio-economic and cultural contexts of biological resources are indigenous. To fulfill the conditions of the Convention on Biodiversity, livelihood strategies, local resource management, forest resource utilization, indigenous knowledge, food and medicinal habits are all of immense importance; they are connected with the biological resources of the terrain.

Moreover, biodiversity conservation is not confined to the conservation of the genetic components of species. It includes the conservation of ecosystem diversity, non-forest diversity, species diversity and ricluness, and the creation of conditions in which diversity can be maintained mainly in a self-supporting way. We must know how conservation appears from the local point of view, and how local community motivations are governed. The most outstanding feature of the situation that faces us is the relation between diversity of output and the sustainability of local survival of the people.

\section{References}

Bhatia, S. and Ashish Kothari (1996). Community register for documenting local community uses of biological diversity. Biodiversity 9, 11-12. Kenya, ELCI.

FAO-UNESCO (1992). Forests and cultures in Asia. FAO-UNESCO Workshop and Project Proposal on Focus. Paris and Bangkok., UNESCO.

NAVDANYA TEAM. (1993). Cultivating diversity: biodiversity conservation and the politics of the Seedu. Report No. 1, Research Foundation for Science, Technology and Natural Resource Policy, India.

Panos Media Briefing (1995). Biodiversity: A matter of extinction, The challenge of protecting the South's biological heritage. Panos Media Brieling No. 17. London, Panos Briefing.

Sandlund, O.T., Hinder, K. and Brown, A.H.D. (1992).Conservation of biodiversity for sustainable development. Norway, Scandinavian University Press.

Shiva, V (1996) Towards a biodiversity-based productivity framework, ILELA Newsletter, Vol. 12, No. 3, pp.22-23

US National Research Council (1992). Conserving biodiversity: a research agenda for development agencies. Washington, DC, National Academy Press

UNEP (1992). Global Biodiversity Sirategy. WRI/UNDP/UNEP.

Wickramasinghe, A. (1995). People and the forest: management of the Adam's Peak Wilderness. Forest Department, Sri Lanka.

Wickramasinghe, A. (1996). Participatory approach for biodiversity conservation. Paper presented at the Seminar on Perspectives in Biodiversity, 25 October, 1996. Colombo, NARESA.

Wickramasinghe, A. (1997). Anthropogenics related to forest management in Sri Lanka. Applied Geography 17 (2). 